\title{
Direct in Vitro Organogenesis From Sprouted Seeds of a Highly Economical and Ecological Valued Tree, Korean Pine
}

Yan Liang ( $\sim$ liangyanyanliang@126.com )

Qiqihar University

Xue Bai

Qiqihar University

Xin Xu

Qiqihar University

Hongguo Xu

Qiqihar University

Jing Wang

Heilongjiang Academy of Agricultural Sciences

Peng Pan

Qiqihar University

\section{Research Article}

Keywords: Pinus koraiensis, in vitro propagation, Shoot organogenesis, Plant growth regulators

Posted Date: June 9th, 2021

DOl: https://doi.org/10.21203/rs.3.rs-589377/v1

License: (1) This work is licensed under a Creative Commons Attribution 4.0 International License.

Read Full License

Version of Record: A version of this preprint was published at Plant Cell, Tissue and Organ Culture (PCTOC) on September 3rd, 2021. See the published version at https://doi.org/10.1007/s11240-02102164-6. 


\section{Direct in vitro organogenesis from sprouted seeds of a highly economical and ecological valued tree, Korean pine}

Yan Liang ${ }^{1,2}, *$, Xue Bai ${ }^{1}$, Xin $\mathrm{Xu}^{1}$, Hongguo $\mathrm{Xu}^{1}{ }^{1}$ Jing Wang ${ }^{3}$ and Peng Pan ${ }^{1}$

School of Life Sciences and A \& F, Qiqihar University, Qiqihar, 161006, China; liangyanyanliang@126.com

2 Provincial Key Laboratory of Resistance Gene Engineering and Protection of Biodiversity in Cold Areas, Qiqihar, 161006, China

Quality and Safety Institute of Agricultural Products, Heilongiiang Academy of Agricultural Sciences, Harbin 150086, China

* Correspondence: liangyanyanliang@126.com

Abstract: The de novo organogenesis system for Korean pine of this economically and ecologically coniferous species was successfully established using sprouted seeds as the original explants. After 30 days of incubation, $92.67 \%$ of explants produced direct shoots on Gupta and Durzan(DCR) medium containing $2 \mathrm{mg} \cdot \mathrm{L}^{-1}$ kinetin (KT) in combination $0.5 \mathrm{mg} \cdot \mathrm{L}^{-1}$ thidiazuron (TDZ) with a maximum of about 15 shoots per explant respectively. We also confirmed the organogenic regeneration pattern by scanning electron microscopy (SEM) observation. For shoot elongation and growth after 60 days of culture, we obtained the highest mean length of $34.99 \mathrm{~mm}$ from DCR basal media supplemented with 6-benzyladenine (6-BA; $\left.0.2 \mathrm{mg} \cdot \mathrm{L}^{-1}\right)$, 1-Naphthaleneacetic acid (NAA; 0.1 $\mathrm{mg} \cdot \mathrm{L}^{-1}$ ), and activated charcoal $\left(\mathrm{AC} ; 1 \mathrm{~g} \cdot \mathrm{L}^{-1}\right)$. The highest rooting percentages of $20.74-21.48 \%$ were observed within two months in the 1/2 DCR medium (major elements halved) enriched with $0.05 \mathrm{mg} \cdot \mathrm{L}^{-1} \mathrm{NAA}$ and $0.5 \mathrm{or} 1 \mathrm{mg} \cdot \mathrm{L}^{-1}$ indole-3-butyric acid (IBA). Rooted plants showed a survival rate of $90.28 \%$ in perlite: peat: vermiculite $=1: 1: 1$ after acclimatization. This protocol is a successful and efficient biotechnological approach to the micropropagation of Korean pine, and these data will be helpful to the clonal propagation and conservation of Korean pine.

Keywords: Pinus koraiensis; in vitro propagation; Shoot organogenesis; Plant growth regulators

\section{Introduction}

Korean pine (Pinus koraiensis Sieb. et Zucc.) is an evergreen coniferous tree species belonging to the Pinus genus and Pinaceae family, a dominant species of the natural mixed coniferous and broadleaf forests in the temperate forests of Northeast China. There are few natural populations of Korean pine sporadically distributed in South Korea, North Korea, Japan, and the Far Eastern region of Russia, where it plays a critical ecological role (Wang et al. 2018). Korean pine is famous for its high economic value, such as producing good quality timber and food for humans due to its riching in unsaturated fatty acids, proteins, carbohydrates, vitamin E, and other mineral nutrients. In addition, its seeds can also be used as industrial raw materials in food, cosmetics, and medicine (Wang et al. 2018; Shpatov et al. 2017; Fan et al. 2019). However, in recent decades, Korean pine in primary forests has been affected by over-harvesting timber and pine nuts. As a result, the natural populations of Korean pine have drastically declined, and the genetic resources of the species have been threatened by deforestation. Korean pine has been classified as a rare and nationally endangered species in China (Yu et al. 2011; Sun et al. 2016). Therefore, determining methods to increase the number of Korean pine trees in forests successfully is essential for improving qualified seedlings. However, under natural conditions, culturing Korean pine excellent seedlings to the desired size by conventional seed propagation approach usually needs 20 years because of their prolonged growing rate and late sexual maturity of this species; besides, the methods of grafted seedlings have also unacceptable mortality rates (Wei et al. 2020). Hence, to preserve the natural resources and ensure a stable and renewable source of Korean pine for ecological and economic purposes, successful and high-quality cultivation of seedlings and planting is imperative.

Fortunately, supplying a large number, high-quality and genetically superior korean pine seedlings by micropropagation technology is generally considered a highly promising approach. The advantage of micropropagation lies in its potential to eventually produce superior mass genotypes rapidly, and it has been used recently for tree improvement and clonal propagation (Haissig et al. 1987; Zhu et al. 2019). However, compared with most angiosperm woody trees, the clonal production of recalcitrance is still a general problem for many conifer species. Nowadays, nearly 40 species from the genus Pinus have been micropropagated (Kalia et al. 2007; Lelu-Walter et al. 2008; Alvarez et al. 2009; Leandro et al. 2013; Zhu et al. 2019). For example, $P$. radiata has been commercially propagated using organogenesis (Menzies $e t$ al. 2000). Direct organogenesis from explants is the best choice for rapid multiplication as it leads to the generation of true-to-type strains. Plantlets develop directly without the callus phase, so the chances of somaclonal variation are minimal in the regenerated plants, better maintaining its elite properties than indirect morphogenesis (Verma et al. 2021).

But unfortunately, to our knowledge, thus far, there are no efficient reproducible protocols for Korean pine in vitro direct shoot organogenesis technique. The in vitro propagation technology of Korean pine is challenging and has low 
efficiency, which significantly limiting asexual propagation. Given this, in this context, Korean pine sprout seed explants were utilized to establish an effective regeneration system through direct adventitious bud organogenesis. The factors influencing adventitious buds formation, elongation, and rooting of Korean pine in vitro were determined. This study can provide clues for constructing a micropropagation system of Korean pine and artificially regulating organogenesis, facilitating propagation of elite seedlings for reforestation and monocultures in this species' production, and laying a foundation for the realization of industrial seedlings of coniferous species.

\section{Materials and Methods}

\subsection{Plant materials and Explant sterilization}

Mature seeds of Korean pine were collected from a single plant of open-pollinated preferred elite families (WH135) in October 2018. The families grew in the Weihe Korean pine Seed Orchard of Heilongjiang Province, northeastern China. These Korean pine seeds harvested in the previous year were stored with moisture sand at $4{ }^{\circ} \mathrm{C}$ until they were used for tissue culture in April 2019. Those healthy Korean pine seeds with cracked seed coats were selected for this experiment (Figure 1 a). Firstly, the sprouted buds from Korean pine seeds were taken out of the outer seed coat, removed the endosperm, washed with detergent for 2-3 min, then transferred into running water for $30 \mathrm{~min}$. Secondly, they were then immersed in $70 \%(\mathrm{v} / \mathrm{v})$ ethanol for $1 \mathrm{~min}$, rinsed with sterile water five times, and then treated with $0.1 \%$ (w/v) $\mathrm{HgCl}_{2}$ for $10 \mathrm{~min}$ by five successive washes with sterile distilled water. The radicle of the sterilized sprouted buds $(1-1.5 \mathrm{~cm})$ was cut off and then placed vertically in the Durzan medium (DCR) medium to induce adventitious shoots according to the morphological direction. All operations after sterilization were carried out on a clean bench.

\subsection{Medium and culture conditions of adventitious bud induction}

The explants (Figure $1 \mathrm{~b}$ ) were inoculated onto DCR basal medium(Gupta and Durzan 1985), which supplemented with different plant growth regulators (PGRs) at different concentrations: thidiazuron (TDZ; 0.2 or $0.5 \mathrm{mg} \cdot \mathrm{L}^{-1}$ ), kinetin $\left(\mathrm{KT} ; 1,2\right.$, or $3 \mathrm{mg} \cdot \mathrm{L}^{-1}$ ) and 1-Naphthaleneacetic acid (NAA; 0 or $0.1 \mathrm{mg} \cdot \mathrm{L}^{-1}$ ), respectively (Table 1 ). In addition, all the mediums were supplemented with $500 \mathrm{mg} \cdot \mathrm{L}^{-1}$ casein hydrolysate $(\mathrm{CH}), 500 \mathrm{mg} \cdot \mathrm{L}^{-1} \mathrm{~L}$-glutamine, $3 \%(\mathrm{w} / \mathrm{v})$ sucrose, and $0.7 \%(\mathrm{w} / \mathrm{v})$ agar. Thirty tissue materials were used for each treatment, and the experiments were repeated three times. After 30 days of culture, the efficiency of PGRs on adventitious bud induction was determined by recording the frequency of responding explants and the mean number of shoots per explant. In addition, the response changes of explants throughout the induction process were also recorded.

2.3. Scanning electron microscopy (SEM) observation of adventitious bud induction

For morphological observations of the different stages of adventitious shoot differentiation, SEM was employed. The materials at different developmental stages were fixed with FAA fixative (formaldehyde: glacial acetic acid: $70 \%$ ethanol = 5:5:90) for more than $48 \mathrm{~h}$ and then washed in distilled water for $30 \mathrm{~min}$. Samples were dehydrated in a graded ethanol series (10\% increments every $20 \mathrm{~min})$, then soaked in a graded amyl acetate series followed by drying on filter paper at room temperature. They were then sputter-coated with gold in a cold-sputtering system. Samples were examined directly and photographed using a scanning electron microscope (Hitachi S-4300N) at $20 \mathrm{kV}$.

\subsection{Axillary bud growth and elongation}

After an initial induction period of 30 days, when induced axillary bud growth was evident (Figure $1 \mathrm{f}$ ), transferred to elongation medium and cultured for an additional 60 days, subcultured to fresh medium every 30 days of culture. The medium was also DCR basic medium supplemented with different concentrations 6-benzyladenine 6-BA $(0,0.2$, 0.5 or $\left.1 \mathrm{mg} \cdot \mathrm{L}^{-1}\right)$, NAA $\left(0.1 \mathrm{mg} \cdot \mathrm{L}^{-1}\right)$, and activated charcoal $\left(\mathrm{AC} ; 0\right.$ or $\left.1 \mathrm{~g} \cdot \mathrm{L}^{-1}\right)$ (Table 2$)$. The addition of sucrose, agar, $\mathrm{CH}$, and L-glutamine were the same as adventitious bud induction treatment. The best medium for shoot elongation was determined based on shoot length.

\subsection{Rooting and domestication of shoots}

After two months of culture, until formed adventitious buds were $1.5-2.0 \mathrm{~cm}$ long (Figure $1 \mathrm{~m}$ ), individual shoots were separated from the multiple shoots and then transferred onto a fresh root-induction medium to promote the root growth. The rooting medium contained different concentrations and combinations of NAA $\left(0,0.05,0.1 \mathrm{or} 0.2 \mathrm{mg} \cdot \mathrm{L}^{-1}\right)$ and indole-3-butyric acid (IBA; 0.5, 1 or $1 \mathrm{mg} \cdot \mathrm{L}^{-1}$ ) or no PGRs, medium without any PGRs was used as a control (CK) (Table 3). In addition, medium also supplemented with $1 \mathrm{~g} \cdot \mathrm{L}^{-1} \mathrm{AC}, 500 \mathrm{mg} \cdot \mathrm{L}^{-1} \mathrm{CH}, 2 \%(\mathrm{w} / \mathrm{v})$ sucrose, and $0.7 \%(\mathrm{w} / \mathrm{v})$ agar. Two months later, the rooting rate and root number $\geq 1 \mathrm{~cm}$ per rooted shoot were individually recorded. After rooting culture, plantlets with visible roots $(\geq 1 \mathrm{~cm})$ were transferred to plastic pots containing sterile peat: perlite: vermiculite $(1: 1: 1 ; \mathrm{v} / \mathrm{v})$ mixture located in a greenhouse. For acclimatization, plantlets were covered with glass beakers for one week before being exposed to greenhouse conditions by removing the cover. A total of 10 subcultured plantlets $(\times 3$ replicates) were collected for rooting induction and domestication. 
The basal medium used in this study was the DCR medium. The $\mathrm{pH}$ of all mediums was adjusted to 5.8 with 0.1 $\mathrm{M} \mathrm{NaOH}$ and $0.1 \mathrm{M} \mathrm{HCL}$ before autoclaving. L-Glutamine was filter sterilized with $0.22 \mu \mathrm{m}$ filters and supplemented into the autoclaved medium when it had cooled to about $50^{\circ} \mathrm{C}$. Other PGRs and additives were added to the medium before sterilization. Cultures for induction of adventitious bud, elongation, and rooting in vitro were all kept in a growth chamber at $22 \pm 2^{\circ} \mathrm{C}$, with a $16 \mathrm{~h}$ photoperiod of fluorescent light $\left(60 \mu \mathrm{mol} \cdot \mathrm{m}^{-2} \cdot \mathrm{s}^{-1}\right)$ provided by cool white fluorescent tubes. Acclimatization was kept in a greenhouse at $22 \pm 2{ }^{\circ} \mathrm{C}$, with $70-80 \%$ relative humidity, and $16 \mathrm{~h}$ photoperiod of 80 $\mu \mathrm{mol} \cdot \mathrm{m}^{-2} \cdot \mathrm{s}^{-1}$ light. All products were purchased from Sigma-Aldrich (Madrid, Spain), except sucrose and AC from Solarbio (Beijing, China).

2.6. Statistical analysis

All the experiments were conducted thrice with randomized design settings. Data were analyzed by using analysis of variance (ANOVA) in SPSS ver. 17.0 software (SPSS Inc., Chicago, Illinois). Significant differences among the means of the treatments were evaluated using Duncan's new multiple range test $(p \leq 0.05)$.

\section{Results}

3.1. Effects of PGRs on in vitro de novo organogenesis of Pinus koraiensis

Organogenesis is the de novo production of plant organs from organized tissues or callus(Thakur and Kanwar 2018). In this study, direct organogenesis occurred in Korean pine was observed (Figure 1). When supplemented with different cytokinins (CKs) and auxins, the differential response towards multiple adventitious bud induction was recorded. The results of shoot induction varied with the type and concentration of PGRs, as depicted in Table 1. On the whole, the addition of CKs supplemented with lower concentrations auxins (or no addition) to the medium promoted the morphogenic response. Compared with CKs alone in the medium, the exogenous application of high concentration CKs along with low concentration auxin did not significantly improve the adventitious bud induction parameters. Therefore, it can be concluded that adding CKs alone was beneficial for the bud formation of Korean pine, and the addition of auxin was not necessary. Among them, the medium supplementing $2 \mathrm{mg} \cdot \mathrm{L}^{-1} \mathrm{KT}$ in combination with 0.5 $\mathrm{mg} \cdot \mathrm{L}^{-1} \mathrm{TDZ}, 0$ or $0.1 \mathrm{mg} \cdot \mathrm{L}^{-1} \mathrm{NAA}$ was proved to be most effective in terms of yielding average 14.67 and 15.33 shoots per explant with adventitious bud induction rate were $92.67 \%$ and $90.66 \%$, respectively after 30 days of incubation, significantly higher than other treatments $(p<0.05)$ (Table 1). Otherwise, compared with TDZ and NAA, suitable KT concentration showed more shoots per explants and adventitious bud induction rate. Of the various treatment tested, with the increase of the KT treatment concentration, Korean pine adventitious buds' induction rate increased first and then decreased. The medium containing $1 \mathrm{mg} \cdot \mathrm{L}^{-1} \mathrm{KT}$, combined with TDZ $\left(0.2\right.$ or $\left.0.5 \mathrm{mg} \cdot \mathrm{L}^{-1}\right)$ and NAA $(0$ or 0.1 $\mathrm{mg} \cdot \mathrm{L}^{-1}$ ), only produced 3.67-6.67 shoots shoot induction rate of $27.4-43.2 \%$. The concentration above or below the optimal dose of KT did not improve the parameters of adventitious buds. Compared with $2 \mathrm{mg} \cdot \mathrm{L}^{-1}$, when KT concentration increased to $3 \mathrm{mg} \cdot \mathrm{L}^{-1}$, both the induction rate of adventitious buds and the number of induced buds decreased significantly, in addition, higher $\mathrm{KT}$ dose $\left(3 \mathrm{mg} \cdot \mathrm{L}^{-1}\right)$ in the medium also led to the development of stunted and clustered buds.

Table 1. Effect of hormone treatment on adventitious bud induction of Korean pine after 30 days of cultures

\begin{tabular}{cccccc}
\hline Number & $\begin{array}{c}\text { KT } \\
\mathbf{m g} \cdot \mathbf{L}^{-\mathbf{1}}\end{array}$ & $\begin{array}{c}\text { TDZ } \\
\mathbf{m g} \cdot \mathbf{L}^{-\mathbf{1}}\end{array}$ & $\begin{array}{c}\text { NAA } \\
\mathbf{m g} \cdot \mathbf{L}^{-\mathbf{1}}\end{array}$ & $\begin{array}{c}\text { Adventitious bud induction } \\
\text { rate (\%) mean }\end{array}$ & $\begin{array}{c}\text { Number of shoots per } \\
\text { explant } \mathbf{m e a n}\end{array}$ \\
\hline 1 & 1 & 0.2 & 0 & $27.4 \pm 1.73 \mathrm{f}$ & $3.67 \pm 0.88 \mathrm{f}$ \\
2 & 1 & 0.2 & 0.1 & $31.75 \pm 2.12 \mathrm{f}$ & $5.33 \pm 0.88 \mathrm{def}$ \\
3 & 1 & 0.5 & 0 & $46.51 \pm 2.06 \mathrm{de}$ & $5.67 \pm 0.88 \mathrm{def}$ \\
4 & 1 & 0.5 & 0.1 & $43.2 \pm 0.64 \mathrm{e}$ & $6.67 \pm 0.67 \mathrm{cde}$ \\
5 & 2 & 0.2 & 0 & $51.9 \pm 1.81 \mathrm{~cd}$ & $9 \pm 0.58 \mathrm{bcd}$ \\
6 & 2 & 0.2 & 0.1 & $53 \pm 0.57 \mathrm{c}$ & $14.67 \pm 0.67 \mathrm{bc}$ \\
7 & 2 & 0.5 & 0 & $92.67 \pm 1.98 \mathrm{a}$ & $15.33 \pm 0.88 \mathrm{a}$ \\
8 & 2 & 0.5 & 0.1 & $90.66 \pm 0.83 \mathrm{a}$ & $9.67 \pm 0.88 \mathrm{~b}$ \\
9 & 3 & 0.2 & 0 & $73.24 \pm 2.26 \mathrm{~b}$ & $8 \pm 1.15 \mathrm{bcd}$ \\
10 & 3 & 0.2 & 0.1 & $53.41 \pm 1.93 \mathrm{c}$ & $3.67 \pm 0.88 \mathrm{f}$ \\
12 & 3 & 0.5 & 0 & $51.73 \pm 1.72 \mathrm{~cd}$ & $4.33 \pm 0.88 \mathrm{ef}$ \\
\hline
\end{tabular}

Means followed by the same letter in each column are not significantly different by Duncan's multiple tests $(p \leq 0.05)$ 
Morphological differences under the induction of Korean pine organogenesis were shown in Figure 1. The first morphological changes were recorded during the 7-10 days of culture when the cotyledons were splayed and turned green, the color of the cotyledon base changed to transparent from slightly green and dilated in the region around the bottom of the cotyledons, where observed multiple small protrusions invisible to the naked eye by stereomicroscopic, indicated that the bud primordium and needle primordia initiated and formed (Figure $1 \mathrm{c}, \mathrm{g}$ ). Otherwise, a small amount of callus was also seen at the location of the hypocotyl. After another ten days of culture, those protrusions showed a further continuous increase in volume and number, just as shown in Figure 1d, which were dense buds cluster of original needles visible to the naked eye. We also observed adventitious shoots at an early development stage, needle primordia with transparent color, and a more evident structure from the cotyledon base by SEM (Figure $1 \mathrm{~h}$ ). On the 30th day of culture, adventitious shoots were formed completely (Figure $1 \mathrm{e}, \mathrm{f}$ ). Those protruded bud spots became more prominent, and the color gradually changed to yellowish. As described in Figure 1i, SEM revealed the leaf sheathlike structure was protecting the shoot meristem (asterisk), and clusters of adventitious shoots formed. Otherwise, we also observed numerous adventitious buds at different development stages on the explant simultaneously, and no vitrification was detected (Figure $1 \mathrm{j}$ ).

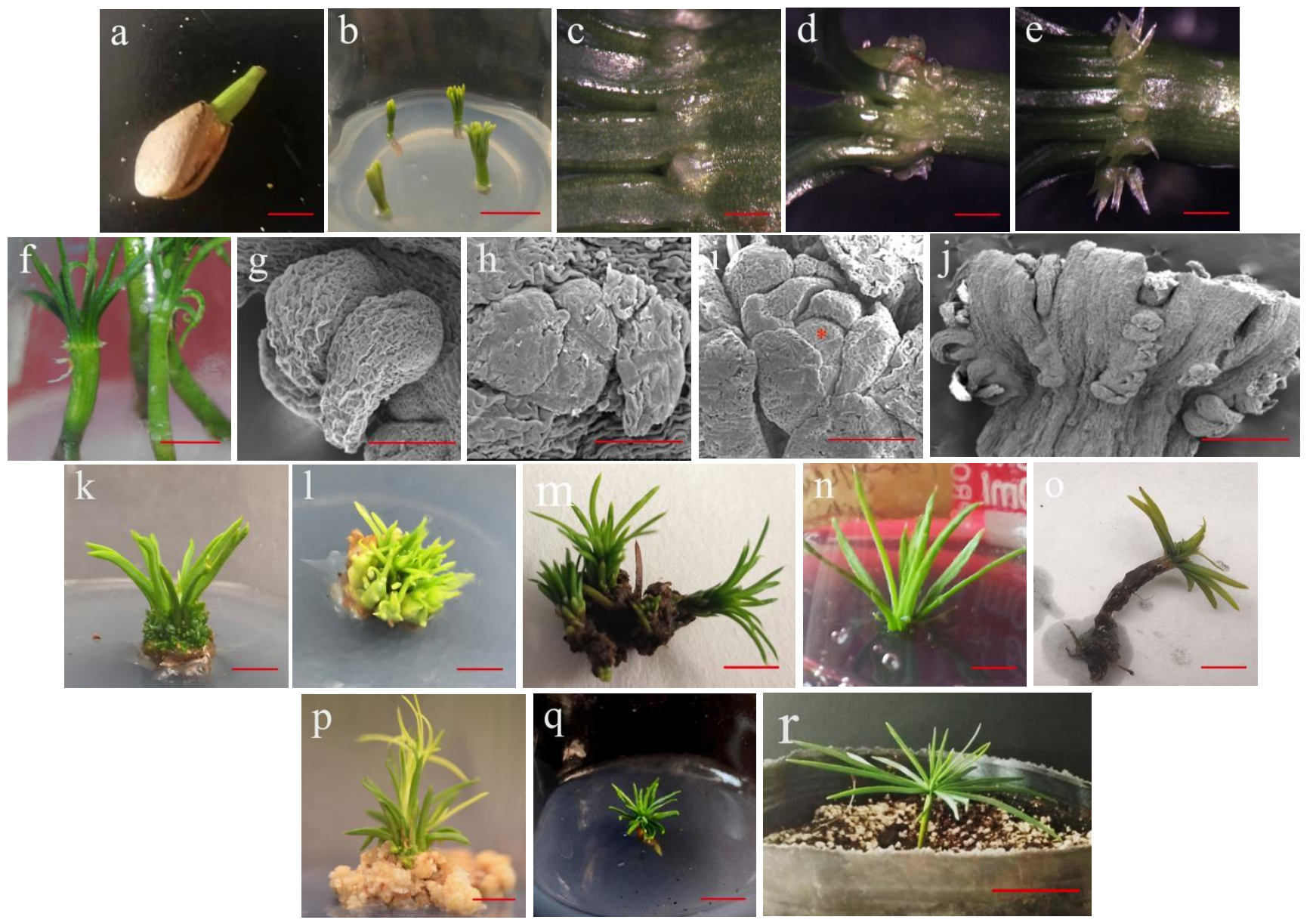

Figure 1. Establishment of the in vitro regeneration system for sprouted seeds explants of Korean pine. (a) the sprouted seeds of Korean pine (bar = $5 \mathrm{~mm}$ ); (b) explants inoculated into adventitious bud induction medium (0d) (bar = $10 \mathrm{~mm})$; (c) adventitious buds of Korean pine obtained by culturing for 10 days (bar = $2 \mathrm{~mm}$ ); $(\mathrm{d})$ adventitious buds of Korean pine obtained by culturing for 20 days (bar = $5 \mathrm{~mm}$ ); (e-f) adventitious buds of Korean pine obtained by culturing for 30 days (bar = $5 \mathrm{~mm}$ ); (g-j) scanning electron microscopy of adventitious shoot formation from cotyledons 10 (g), 20 (h), and 30 (i, j) days culture, respectively; (g) adventitious bud primordium and needle primordia just also formed after 7-10 days culture (bar $=2 \mathrm{~mm})$. (h) adventitious shoot primordia at early stage of development after 20 days culture (bar $=2 \mathrm{~mm}$ ); (i) clusters of adventitious shoots formed and the leaf sheath-like structure protecting the shoot meristem $(*)$ after 30 days culture (bar $=2 \mathrm{~mm}$ ); (j) numerous adventitious buds at different development stages simultaneously after 30 days culture (bar $=3 \mathrm{~mm}) ;(\mathrm{k})$ adventitious buds of Korean pine after elongation for 20 days (bar $=5 \mathrm{~mm}) ;(\mathrm{l})$ adventitious buds of Korean pine after elongation for 40 days (bar $=5 \mathrm{~mm})$; $(\mathrm{m})$ adventitious buds of Korean pine after elongation for 60 days $(\mathrm{bar}=10 \mathrm{~mm})$; $(\mathrm{n})$ isolated individual dventitious buds that were used for rooting (bar = $10 \mathrm{~mm})$; $(\mathrm{o})$ the deformed adventitious roots were produced $(\mathrm{bar}=8 \mathrm{~mm}) ;(\mathrm{p})$ a large amount of callus formed during the rooting process $(\mathrm{bar}=10 \mathrm{~mm}) ;(\mathrm{q})$ 
roots were formed from elongated adventitious shoots after 60 days (bar = $15 \mathrm{~mm})$; (r) plantlets established in potting substrate for 30 days $($ bar $=25 \mathrm{~mm})$

\subsection{Effects of PGRs on Shoot elongation and growth of Korean pine}

Once those in vitro-established tender buds were transferred to shoot elongation media, they showed faster growth than the adventitious bud induction stage. According to the results of means comparison analysis, the adventitious buds showed different responses on various shoot elongation media. In general, under eight treatments, with the concentration of 6-BA treatment increased, the length of adventitious buds first increased and then decreased. When 6-BA is not added, regardless of whether AC is added, the adventitious buds elongation was not very obvious, and the average bud length was $<5 \mathrm{~mm}$ in 60 days. After 60 days of culture, the highest mean length (34.99 mm) of Korean pine was obtained from DCR basal media supplemented with 6-BA $\left(0.2 \mathrm{mg} \cdot \mathrm{L}^{-1}\right)$, NAA $\left(0.1 \mathrm{mg} \cdot \mathrm{L}^{-1}\right)$, and AC $\left(1 \mathrm{~g} \cdot \mathrm{L}^{-1}\right)($ Figure 2 $\mathrm{m})$, significantly higher than other treatments $(p<0.05)$, followed by AC-free treatment $(26.54 \mathrm{~mm})($ Table 2$)$. Meanwhile, these in vitro seedlings thrived. We also found that appropriate 6-BA addition concentration was more efficient for bud elongation when the 6-BA concentration increased to $0.5 \mathrm{mg} \cdot \mathrm{L}^{-1}$ or $1 \mathrm{mg} \cdot \mathrm{L}^{-1}$, regardless of whether it contained AC, the average shoot length decreased again $(<18 \mathrm{~mm})$, and the needles were tiny and grew slowly. Our results indicate that the complementary of low concentration of 6-BA and NAA was efficient for promoting rapid growth and elongation of shoots in Korean pine. Figure $1 \mathrm{k}, 11$ and $1 \mathrm{~m}$ showed the adventitious buds after elongation treatment for 20, 40 , and 60 days, respectively. It can be seen that the adventitious buds of 20 days were slightly elongated, some meristems further developed into shoot buds, and the buds of 40 days were more obvious; at 60 days, the bud length reached its maximum (Table 2).

Table 2. Effect of hormone treatment on adventitious bud elongation of Korean pine after 60 days of cultures

\begin{tabular}{ccccc}
\hline Number & $\begin{array}{c}\mathbf{6 - B A} \\
\mathbf{m g} \cdot \mathbf{L}^{-\mathbf{1}}\end{array}$ & $\begin{array}{c}\text { NAA } \\
\mathbf{m g} \cdot \mathbf{L}^{-\mathbf{1}}\end{array}$ & $\begin{array}{c}\mathbf{A C} \\
\mathbf{g} \cdot \mathbf{L}^{\mathbf{- 1}}\end{array}$ & $\begin{array}{c}\text { Mean shoots length } \\
(\mathbf{m m})\end{array}$ \\
\hline 1 & 0 & 0.1 & 0 & $4.74 \pm 0.13 \mathrm{f}$ \\
2 & 0 & 0.1 & 1 & $4.92 \pm 0.11 \mathrm{f}$ \\
3 & 0.2 & 0.1 & 0 & $26.54 \pm 0.51 \mathrm{~b}$ \\
4 & 0.2 & 0.1 & 1 & $34.99 \pm 0.42 \mathrm{a}$ \\
5 & 0.5 & 0.1 & 0 & $16.81 \pm 0.46 \mathrm{~d}$ \\
6 & 0.5 & 0.1 & 1 & $17.64 \pm 0.24 \mathrm{c}$ \\
7 & 1 & 0.1 & 0 & $5.6 \pm 0.06 \mathrm{e}$ \\
8 & 1 & 0.1 & 1 & $4.43 \pm 0.15 \mathrm{~g}$ \\
\hline
\end{tabular}

Means followed by the same letter in each column are not significantly different by Duncan' multiple tests $(p \leqslant 0.05)$

\subsection{Ex vitro rooting and acclimatization of the shoots}

Induction of roots in vitro is an essential step to establish tissue culture derived from plantlets to the soil. Application of exogenous auxin usually can solve the problem of root induction in rooting recalcitrance species (Wen et al. 2020). Generally, the most effective auxins for in vitro rooting are IBA and NAA. In addition, differences in species and genotypes also affect the rooting effect (Hesami and Daneshvar 2019). In our experiments, to obtain hardened plantlets, isolated shoots (1.5 to $2.0 \mathrm{~cm}$ long) were excised from adventitious shoots after 60 days of elongation culture and then cultured in the rooting medium (Figure $1 \mathrm{n}$ ). Here, the rooting rate was individually recorded. Of the 13 tested treatments, the average rooting percentages vary from 0 to $21.48 \%$, and only one true root $\geqslant 1 \mathrm{~cm}$ per rooted shoot is formed. The highest rooting percentages was $20.74-21.48 \%$ when $0.05 \mathrm{mg} \cdot \mathrm{L}^{-1} \mathrm{NAA}$ and $0.5 \mathrm{or} 1 \mathrm{mg} \cdot \mathrm{L}^{-1} \mathrm{IBA}$ were used, significantly higher than other treatments (Table 3). In addition, the medium without any PGRs (CK) did not induce roots from elongated shoots. When NAA treatment concentration increased to higher than $0.1 \mathrm{mg} \cdot \mathrm{L}^{-1}$, it was observed that a large amount of callus was formed at the base of adventitious buds, and many deformed adventitious roots were produced from these calli (Figure $1 \mathrm{o}$ ), especially in treatments with NAA at $0.2 \mathrm{mg} \cdot \mathrm{L}^{-1}$ and IBA at $0.5,1$ or $2 \mathrm{mg} \cdot \mathrm{L}^{-1}$, respectively, where no roots were produced, but a lot of calli was produced at the location where the roots were formed (Figure 1 p), in vitro rooting percentages were only between $0-6.67 \%$ treated with IBA alone; also, a small amount of callus appeared on their base. Figure $1 \mathrm{q}$ are the rooted shoots after rooting treatment $60 \mathrm{~d}$, and the rooted shoots were acclimatized in the sterilized matrix. After one month of growth in the greenhouse, the survival of the weaned plants was $90.28 \%$, and all regenerated plantlets showed normal growth and morphology under greenhouse conditions (Figure $1 \mathrm{r})$. 
Table 3. Effect of auxin treatment on rooting capacity of Korean pine after 60 days of cultures

\begin{tabular}{cccc}
\hline Number & $\begin{array}{c}\text { NAA } \\
\mathbf{m g} \cdot \mathbf{L}^{-\mathbf{1}}\end{array}$ & $\begin{array}{c}\text { IBA } \\
\mathbf{m g} \cdot \mathbf{L}^{-\mathbf{1}}\end{array}$ & $\begin{array}{c}\text { Rooting rate explant } \\
\text { mean }(\%)\end{array}$ \\
\hline CK & 0 & 0 & $0.00 \pm 0 \mathrm{c}$ \\
1 & 0 & 0.5 & $0.00 \pm 0 \mathrm{c}$ \\
2 & 0 & 1 & $6.67 \pm 2.17 \mathrm{~b}$ \\
3 & 0 & 2 & $6.67 \pm 2.38 \mathrm{~b}$ \\
4 & 0.05 & 0.5 & $20.74 \pm 0.52 \mathrm{a}$ \\
5 & 0.05 & 1 & $21.48 \pm 0.52 \mathrm{a}$ \\
6 & 0.05 & 2 & $6.67 \pm 2.17 \mathrm{~b}$ \\
7 & 0.1 & 0.5 & $10.37 \pm 0.35 \mathrm{~b}$ \\
8 & 0.1 & 1 & $11.11 \pm 2.72 \mathrm{~b}$ \\
9 & 0.1 & 2 & $0.00 \pm 0.00 \mathrm{c}$ \\
10 & 0.2 & 0.5 & $0.00 \pm 0.00 \mathrm{c}$ \\
11 & 0.2 & 1 & $0.00 \pm 0.00 \mathrm{c}$ \\
12 & 0.2 & 2 & $0.00 \pm 0.00 \mathrm{c}$ \\
\hline
\end{tabular}

Initiation percentages for individual replicates were transformed by $\arcsin \sqrt{x} / 100$ for ANOVA.

Means followed by the same letter in each column are not significantly different by Duncan's multiple tests $(p \leq 0.05)$

\section{Discussion}

\subsection{De novo shoot organogenesis from Korean pine sprouted seeds explants}

In long-lived trees such as conifers, despite considerable amounts of research-derived plantlets by indirect or direct organogenesis, most coniferous species are still regarded as extremely difficult to regenerate (Bonga 2017; Sarmast 2017). Nevertheless, essential steps in establishing in vitro micropropagation are the induction and multiplication of shoots (Li et al. 2018). Being a commercially and economically important tree species, developing a robust regeneration protocol for Korean pine is urgently needed. In the present study, the direct organogenesis of Korean pine from sprouted seed explants was achieved, and confirmed the organogenic regeneration pattern by SEM observation. This propagation pathway by direct organogenesis has also been proven to have less risk of somaclonal variations than indirect organogenesis (Verma et al. 2017; Zayova et al. 2010).

The formation of adventitious shoots is a complex process that involves the participation of PGRs, mainly auxins and CKs, with multiple signaling pathways (Sang et al. 2018; Tian et al. 2018; Ikeuchi et al. 2019). Compared with auxins, CKs are involved in bud breakage, cell division, shoot initiation, and multiplication from explants, which are more frequently applied to induce in vitro shoot organogenesis (Mazri 2015; Zhang et al. 2018; Ayala et al. 2019). The exogenous CKs application facilitates the explant to reach an optimum cytokinin: auxin ratio for de novo meristem formation (Alvarez et al. 2020). Among them, 6-BA, KT, and TDZ are routinely used CKs most efficiently (Khanam et al. 2020).

Our results were similar to reports of other woody trees. A combination of a higher cytokinin-to-auxin ratio to the medium was beneficial to induce multiple shoots (Zhu et al. 2019; Zhu et al. 2010; Tippani et al. 2013; Ahmad et al. 2020). In our study, compared with CKs alone in the medium, exogenous application of high concentration CKs (KT and TDZ) along with a low dose of auxins did not significantly improve the adventitious bud induction parameters of Korean pine. Therefore, it can be concluded that adding CKs alone was considered essential to sustain the organogenic response of Korean pine explants, whereas the addition of auxin was not necessary. In addition, compared with TDZ and NAA, suitable KT concentration showed more shoots per explants during the adventitious buds induction of Korean pine, and above or below the optimal dose of KT did not show any improvement in parameters of adventitious buds, which is in line with previous studies that exceeding optimal KT levels inhibits bud proliferation(Akbaş et al. 2009; Arab et al. 2014). TDZ is a phenyl urea-type cytokinin that mimics the activity of both auxin and cytokinin, which are the most preferably used cytokinins in some woody plant regeneration systems (Dewir et al. 2018; Rukaya et al. 2021). Previous studies described TDZ was used solely for indirect organogenesis and proved more effective for the shoot induction process in a range of plants in vitro (Khanam et al. 2018; Wu et al. 2020; Syeed et al. 2021). However, in our study, TDZ in combination with KT was more conducive to the direct adventitious buds formation of Korean pine, which can be explained by the fact that TDZ is highly stable and regulates endogenous hormones, and shows the activity of both 
auxins as well as cytokinin, similarly mentioned in the literature (Dewir et al. 2018; Dey et al. 2012) also found that TDZ appears to stimulate cells in the apical meristem to divide, multiply, and develop so that bud differentiation occurred. SEM results also confirmed the direct organogenesis pathway in our study, showed shoots arising from cotyledons base of sprouted bud explants.

Nowadays, successful micropropagation has been reported in many pine species using various explants, such as mature zygotic embryos (Cortizo et al. 2009; Montalbán et al. 2011; Stojičić et al. 2012), cotyledons (Alvarez et al. 2009), seedling explants (Zhu et al. 2010; Hargreaves et al. 2005; Nunes et al. 2018), and in some cases, explants from mature trees (Cortizo et al. 2009; Parasharami et al. 2003). Besides, the choice of explant is believed to affect in vitro response differently. In 2018-2019, we also took mature zygotic embryos of Korean pine as explants to induce adventitious bud, but the effect is significantly lower than that of sprouted seeds.

\subsection{Shoot elongation and growth of in vitro Pinus koraiensis}

In the second step of the culture procedure, adventitious buds of Korean pine were transferred onto the shoot elongation medium. After 60 days of culture, our data gave better results regarding growth parameters (the length and number of the shoots). Overall, PGRs had a significant effect on the length and number of the shoots. The in vitroestablished buds elongation growth was significantly accelerated, and low concentration combinations of 6-BA and NAA were found to be efficient for promoting rapid growth and elongation of Korean pine adventitious buds; among them, the most extended shoots were generated on the DCR basal media containing 6-BA $\left(0.2 \mathrm{mg} \cdot \mathrm{L}^{-1}\right)$, NAA $(0.1$ $\left.\mathrm{mg} \cdot \mathrm{L}^{-1}\right)$, and $\mathrm{AC}\left(1 \mathrm{~g} \cdot \mathrm{L}^{-1}\right)$. Therefore, our results agreed with a combination of a higher cytokinin-to-auxin ratio in medium be efficient for successful shoot inducing morphogenic response and stimulating shoot proliferation; however, for shoot elongation in Korean pine, lower concentrations of the same PGRs is more appropriate, which was also in agreement with those plant micropropagation studies that have demonstrated for promoting bud elongation, medium without plant growth regulators (Zhu et al. 2019; Stojičić et al. 2012), or with a lower level of cytokinin with auxin (Tanf et al. 2004; Zhang et al. 2006; Zhu et al. 2007; Schaller et al. 2015) or 0.1-0.5\% AC (Zhu et al. 2019; Stojičić et al. 2012) was usually were proven to be effective. It is worth noting that the rate of shoot multiplication and extent of shoot elongation observed here are better than previously published reports on other pine micropropagation(Zhu et al. 2019; Montalbán et al. 2011; Stojičić et al. 2012).

\subsection{Rooting and acclimatization of Pinus koraiensis microshoots}

As we all know, many coniferous species have a low capacity for rooting in vitro, and the most common problem encountered in the micropropagation of pines is adventitious root formation, and also because of this, reducing the possibilities of applying these techniques for large scale micropropagation(Bonga 2017). Generally, auxins play an essential role in regulating adventitious root formation, and IBA or NAA are often used to promote in vitro rooting (Kalia et al. 2007; Alvarez et al. 2009; Wang and Yao 2019a; Wang and Yao 2019b). After two months of cultivation on rootpromoting medium, the highest rooting percentages were $<30 \%$ in our present study. However, NAA concentrations to higher-than-optimal levels $\left(0.1\right.$ or $\left.0.2 \mathrm{mg} \cdot \mathrm{L}^{-1}\right)$ induced a large amount of undesirable callus, and a few deformed adventitious roots were produced at the basal end of the microshoot, indicated that the appearance of callus led to poor rooting. Our findings were consistent with the previous report when high concentration NAA was used to induce adventitious roots in Pinus massoniana, a mass of callus from which root primordia differentiated was produced on the base of most shoots (Zhang et al. 2006). In addition, when treated with IBA singly, a small amount of callus appeared and resulted in poor rooting (very few or no roots). Similarly, the recent study of in vitro rooting from Pterocarpus marsupium also found that beyond the optimum dose of IBA induced undesirable callus at the basal end of microshoot, and no rooting was observed (Ahmad et al. 2020). Otherwise, for applied PGRs in vitro rooting, there are some different results, supplementation with $1.2 \mathrm{uM}$ NAA in the medium was effective for rooting induction in $P$. massoniana (Wang and Yao 2019b), most of the clones from Pinus densiflora rooted on medium supplemented with $0.2 \mathrm{mg} \cdot \mathrm{L}^{-1} \mathrm{NAA}(\mathrm{Zhu}$ et al. 2019). IBA was also reported to be better than with NAA or a mixture of both auxins in vitro rooting (Zhu et al. 2007), in contrast to this, IBA $\left(2 \mathrm{mg} \cdot \mathrm{L}^{-1}\right)$ application with NAA $\left(0.1 \mathrm{mg} \cdot \mathrm{L}^{-1}\right)$ was a preferable alternative than IBA only for the Ficus religiosa root induction, subsequent development of the induced roots usually proceeded (Hesami and Daneshvar 2019). Our study is consistent with the F. religiosa research using hormone types; whereas, the concentration combination is different, which can be explained due to differences in coniferous species that lead to different auxins response for in vitro rooting. In addition, those plantlets in the present study showed a high capacity for transference to the ex vitro environment.

However, unlike pine species, some other tree species are prone to rooting and occasionally show spontaneous in vitro rooting of elongated microshoots (Sarkar and Jha 2017). Medium devoid of PGRs or hormone-free AC produce 
higher roots than with PGRs addition. The stimulatory effect of AC on rooting may involve providing a dark environment conducive for the accumulation of auxins or cofactors and / or adsorption of inhibitory substances (e.g., phenolics) and excess hormones (auxins or CKs) carried over from the previous media(Verma et al. 2021). Therefore, in our study, $0.2 \% \mathrm{AC}$ is added to all rooting treatments. However, contrary to earlier reports, our results indicated that culturing on a medium containing $0.2 \%$ AC hormone-free did not significantly promote the formation of adventitious roots.

In addition to PGRs type and concentration, other parameters such as plant species, genotype also affect the in vitro root induction procedure. Our results indicated that although a small part of the plants was rooted in the tested medium combinations, root formation was occasionally observed and rarely. Compared with Pinus peuce (Stojičić et al. 2012), Pinus densiflora (Zhu et al. 2019), and P. massoniana (Wang and Yao 2019b), korean pine may be a difficult coniferous species for in vitro rooting in micropropagation. Therefore, further studies on in vitro rooting are necessary.

\section{Conclusions}

Plant multiplication in vitro proved to be very efficient for large-scale propagation of many tree species, providing a more valuable and rapid way than the traditional cutting procedure. Nevertheless, the development of in vitro protocols for coniferous species is still challenging because of such factors as recalcitrance. This study shows that the de novo organogenesis system for Korean pine by adventitious buds formation was successfully established using sprouted seeds as the original explants, constituting the first report for this economically and ecologically recalcitrance coniferous species with a high-frequency and cost-effective regeneration technique. Importantly, direct organogenesis leads to the generation of true-to-type strains to avoid callus phase organization and have fewer chances of somaclonal variation than indirect organogenesis. We believe that these data will be helpful in future research for rapid micropropagation and conservation of Korean pine, and they might also facilitate the development of biotechnological tools to study such coniferous species.

Author Contributions: L.Y. designed the experiment and performed technical guidance. B.X.and X.X. wrote the manuscript and assisted in the data analysis. X. HG. and W.J. supervised the experimental process. P.P. collected plant materials and investigation. All authors participated in the experimental process. All authors have read and agreed to the published version of the manuscript.

Compliance with ethical standards: We confirm that this manuscript has not been published elsewhere and is not being considered elsewhere. All co-authors have contributed to the work, seen and agreed with the contents of the manuscript. No conflict of interest exists in the submission of this manuscript.

Funding: This research was supported by grants from the National Natural Science Funds of China (Grant No.31800515); the Foundation of Heilongjiang Province of China Educational Committee (Grant No.135109253); Qiqihar Science and Technology Development Funds of China (NYGG-201913, Qiqihar, China).

\section{References}

Ahmad A, Anis M, Khanam MN, Alatar AA (2020) Direct shoot organogenesis from shoot tip explants of a highly medicinal valued tree Pterocarpus marsupium Roxb.In Vitro Cell Dev Biol - Plant 56:670-681. DOI: 10.1007/s11627-020-10115-7

Akbaş H, Dane F, Merić C (2009) Effect of nickel on root growth and the kinetics of metal ions transport in onion(Allium cepa)root. Indian J Biotechnol 46:332-6. DOI:10.1134/S1607672909040152

Alvarez JM, Bueno N, Cuesta C, Feito I, Ordás RJ (2020) Hormonal and gene dynamics in de novo shoot meristem formation during adventitious caulogenesis in cotyledons of Pinus pinea. Plant Cell Rep 39(3):527-541. DOI: 10.1007/s00299-020-02508-0

Alvarez JM, Majada J, Ordas RJ (2009) An improved micropropagation protocol for maritime pine (Pinus pinaster Ait.) isolated cotyledons. Forestry 82:175-184. DOI: 0.1093/forestry/cpn052

Arab MA, Yadollahi A, Shojaeiyan A, Shokri S, Ghojah SM (2014) Effects of nutrient media, different cytokinin types and their concentrations on in vitro multiplication of $\mathrm{G} \times \mathrm{N} 15$ (hybrid of almond $\times$ peach) vegetative rootstock. Journal of Genetic Engineering and Biotechnology 12:81-87. DOI: 10.1016/j.jgeb.2014.10.001

Ayala PG, Brugnoli EA, Luna CV, González AM, Pezzutti R, Sansberro PA (2019) Eucalyptus nitens plant regeneration from seedling explants through direct adventitious shoot bud formation. Trees - Struct. Funct 33:1667-1678. DOI: 10.1007/s00468-019-01888-5

Bonga JM (2017) Can explant choice help resolve recalcitrance problems in in-vitro propagation, a problem still acute, especially for adult conifers? Trees 31:781-789. DOI: 10.1007/s00468-016-1509-z

Cortizo M, Diego ND, Moncaleán P, Ordás RJ (2009) Micropropagation of adult stone pine (Pinus pinea L.). Trees 23:835-842. DOI: 10.1007/s00468-009-0325-0

Dewir YH, Nurmansya, Naidoo Y, Teixeira D (2018) Thidiazuroninduced abnormalities in plant tissue cultures. Plant Cell Rep 37:1451-1470. DOI: 10.1007/s00299-018-2326-1

Dey M, Bakshi S, Galiba G, Sahoo L, Panda SK (2012) Development of a genotype independent and transformation amenable regeneration system from shoot apex in rice (Oryza sativa spp. indica) using TDZ. 3 Biotech 2:233-240. DOI: 10.1007/s13205-012-0051-y 
Fan X, Chengjiang R, Zhang W, Ding J (2019,) Dynamic changes of oil content in Pinus koraiensis seed during development and fatty acid composition of its oil. China Oils and Fats 44:118-120.

Gupta PK, Durzan DJ (1985) Shoot multiplication from mature trees of douglas-fir (Pseudotsuga menziesii) and sugar pine (Pinus lambertiana). Plant Cell Rep 4:177-179. DOI: 10.1007/BF00269282

Haissig BE, Nelson ND, Kidd GH (1987) Trends in the Use of Tissue Culture in Forest Improvement. Nat Biotechnol 5:52-59. DOI: 10.1038/nbt0187-52

Hargreaves CL, Grace LJ, Van der Maas SA, Menzies MI, Kumar S, Holden DG, Foggo MN, Low CB, Dibley MJ (2005) Comparative in vitro and early nursery performance of adventitious shoots from cryopreserved cotyledons and axillary shoots from epicotyls of the same zygotic embryo of control-pollinated Pinus radiata. Can J Forest Res 35:2629-2641. DOI: 10.1139/x05-178

Hesami M, Daneshvar MH, Yoosefzadeh-Najafabadi M (2019) An efficient in vitro shoot regeneration through direct organogenesis from seedling-derived petiole and leaf segments and acclimatization of Ficus religiosa. J Forest Res 30:807-815. DOI: 10.1007/s11676018-0647-0

Ikeuchi M, Favero DS, Sakamoto Y, Iwase A, Coleman D, Rymen B, Sugimoto K (2019) Molecular mechanisms of plant regeneration. Auun Rev Plant Biol 70(1). DOI: 10.1146/annurev-arplant-050718-100434

Kalia RK, Arya S, Kalia S, Arya ID (2007) Plantlet regeneration from fascicular buds of seedling shoot apices of Pinus roxburghii Sarg. Biol Plantarum 51:653-659. DOI: 10.1007/s10535-007-0138-1

Khanam MN, Anis M (2018) Organogenesis and efficient in vitro plantlet regeneration from nodal segments of Allamanda cathartica L. using TDZ and ultrasound assisted extraction of quercetin. Plant Cell Tiss Org Cult 134:241-250. DOI: 10.1007/s11240-018-1416-7 Khanam MN, Javed SB, Anis M, Alatar AA (2020) Meta-topolin induced in vitro regeneration and metabolic profiling in Allamanda cathartica L. Ind Crop Prod 145:111944. DOI: 10.1016/j.indcrop.2019.111944

Leandro F, Oliveira LFD, Quoirin M, Koehler HS, Amano E, Higa AR, Ribas LLF (2013) Propagation from axillary buds and anatomical study of adventitious roots of Pinus taeda L. Academic Journals 12:5413-5422. DOI: 10.5897/AJB2012.2960

Lelu-Walter MA, Bernier-Cardou M, Klimaszewska K (2008) Clonal plant production from self- and cross-pollinated seed families of Pinus sylvestris (L.) through somatic embryogenesis. Plant Cell Tiss Org Cult 92:31-45. DOI: 10.1007/s11240-007-9300-x

Li JW, Ozudogru EA, Li J, Wang MR, Bi WL, Lambard IM, Wang QC (2018) Cryobiotechnology of forest trees: recent advances and future prospects. Biodivers Conserv 27:795-814. DOI: 10.1007/s10531-017-1481-y

Mazri MA (2015) Role of cytokinins and physical state of the culture medium to improve in vitro shoot multiplication.; rooting and acclimatization of date palm (Phoenix dactylifera L) cv. Boufeggous. Plant Biochem Biotechnol 4: 268-275. DOI: 10.1007/s13562-0140267-5

Menzies MI, Holden DG, Klomp BK (2000) Recent trends in nursery practice in New Zealand. New Forest 22:3-17. DOI: 10.1023/A:1012027013173

Montalbán IA, De Diego N, Moncalea'n P (2011) Testing novel cytokinins for improved in vitro adventitious shoots formation and subsequent ex vitro performance in Pinus radiata. Forestry 84:363-373. DOI: 10.1093/forestry/cpr022

Nunes S, Sousa D, Pereira VT, Correia S, Marum L, Santos C, Dias MC (2018) Effificient protocol for in vitro mass micropropagation of slaksh pine. In Vitro Cell Dev Biol - Plant 54(2):175-183. DOI: 10.1007/s11627-018-9891-4

Parasharami VA, Poonawala IS, Nadgauda RS (2003) Bud break and plantlet regeneration in vitro from mature trees of Pinus roxburghii Sarg. Curr Sci India 84:203-208.

Rukaya S, Mujib A, Malik MQ, Mamgain J, Ejaz B, Gulzar B, Zafar N (2021) Mass propagation through direct and indirect organogenesis in three species of genus Zephyranthes and ploidy assessment of regenerants through flow cytometry. Mol Biol Rep 48:513526. DOI: $10.1007 / \mathrm{s} 11033-020-06083-1$

Sang YL, Cheng ZJ, Zhang XS (2018) Plant stem cells and de novo organogenesis. New Phytol 218, 1334-1339. DOI: 10.1111/nph.15106 Sarkar S, Jha S (2017) Morpho-histological characterization and direct shoot organogenesis in two types of explants from Bacopa monnieri on unsupplemented basal medium. Plant Cell Tiss Org Cult 130:435-441. DOI: 10.1007/s11240-017-1231-6

Sarmast MK (2018) In vitro propagation of conifers using mature shoots. J Forest Res 29:565-574. DOI: CNKI:SUN: LYYJ.0.2018-03001

Schaller EG, Bishopp A, Kieberc JJ (2015) The yin-yang of hormones: cytokinin and auxin interactions in plant development. Plant Cell 27:44-63. DOI: 10.1105/tpc.114.133595

Shpatov AV, Popov SA, Salnikova OI, Kukina TP, Shmidt EN, Um BH (2017) Composition and bioactivity of lipophilic metabolites from needles and twigs of Korean and Siberian Pinus (Pinus koraiensis Siebold \& Zucc. and Pinus sibirica Du Tour). Chem Biodivers 14(2). DOI: $10.1002 / \mathrm{cbdv} .201600203$

Stojičić D, Janošević D, Uzelac B, Čokeša V, Budimir S (2012) Micropropagation of Pinus peuce. Biol. Plant 56:362-364. DOI: 10.1007/s10535-012-0099-x

Sun Y, Zhu J, Sun OJ, Yan Q (2016) Photosynthetic and growth responses of Pinus koraiensis seedlings to canopy openness: Implications for the restoration of mixed-broadleaved Korean pine forests. Environ. Exp. Bot 129:118-126. DOI: 10.1016/j.envexpbot.2016.02.005

Syeed R, Mujib A, Malik MQ, Mamgain J, Ejaz B, Gulzar B, Zafar N (2021) Mass propagation through direct and indirect organogenesis in three species of genus Zephyranthes and ploidy assessment of regenerants through flow cytometry. Mol Biol Rep 48:513-526. DOI: 10.1016/j.envexpbot.2016.02.005 
Tang W, Harris LC, Outhavong V, Newton RJ ( 2004) The effect of different plant growth regulators on adventitious shoot formation from Virginia pine (Pinus virginiana) zygotic embryo explants. Plant Cell Tiss Org Cult 78:237-240. DOI: 10.1023/B: TICU.0000025658. 73970.57

Thakur K, Kanwar K (2018) In vitro plant regeneration by organogenesis from leaf callus of carnation.; Dianthus caryophyllus L. cv. 'master.' P Natl A Sci India B 88:1147-1155. DOI: 10.1007/s40011-017-0851-2

Tian X, Zhang C, Xu J (2018) Control of cell fate reprogramming towards de novo shoot organogenesis. Plant Cell physiology 59:708714. DOI: $10.1093 /$ pcp/pcx207

Tippani R, Vemunoori AK, Yarra R, Nanna RS, Abbagani S, Thammidala C (2013) Adventitious shoot regeneration from immature zygotic embryos of Indian Kino tree (Pterocarpus marsupium Roxb.) and genetic integrity analysis of in vitro derived plants using ISSR markers. Hortic Environ Biote 54:531-537. DOI: 10.1007/s13580-013-0161-4

Verma V, Zinta G, Kanwar K (2021) Optimization of efficient direct organogenesis protocol for Punica granatum L. cv. Kandhari kabuli from mature leaf explants. In Vitro Cell Dev Biol - Plant 57:48-59. DOI: 10.1007/s11627-020-10111-x

Wang L, Li X, Wang H (2018) Physicochemical properties bioaccessibility and antioxidant activity of the polyphenols from pine cones of Pinus koraiensis. Int J Biol Macromol 126:385-391. DOI: 10.1016/j.ijbiomac.2018.12.145

Wang Y, Yao RL ( 2019a) Increased endogenous indole-3-acetic acid: abscisic acid ratio is a reliable marker of Pinus massoniana rejuvenation. Biotech Histochem 94:546-553. DOI: 10.1080/10520295.2019.1608468

Wang Y, Yao R (2019b) Optimization of rhizogenesis for in vitro shoot culture of Pinus massoniana Lamb. J Forestry Res 32:203-209. DOI: 10.1007/s11676-019-01076-8

Wei H, Chen G, Chen X, Zhao H (2020) Growth and nutrient uptake in Aralia elata seedlings exposed to exponential fertilization under different illumination spectra. Int J Agric and Biol 23:644-652. DOI: 10.17957/IJAB/15.1336

Wen SS, Chen L, Tian RN (2020) Micropropagation of tree peony (Paeonia sect. Moutan): A review. Plant Cell Tiss Org Cult 141:1-14. DOI: 10.1007/s11240-019-01747-8

Wu Q, Yang H, Sun Y, Hu J, Zou L (2020) Organogenesis and high-frequency plant regeneration in Caryopteris terniflora Maxim. using thidiazuron. In Vitro Cell Dev Biol - Plant 57:39-47. DOI: 10.1007/s11627-020-10114-8

Yu DP, Zhou L, Zhou WM, Ding H, Wang QW, Wang Y, Wu XQ, Dai LM (2011) Forest management in Northeast China: History.; problems.; and challenges. Environ Manage 48:1122-1135. DOI: 10.1007/s00267-011-9633-4

Zayova E, Vassilevska-Ivanova R, Stoeva D, Kraptchev B (2010) Somaclonal variations through indirect organogenesis in eggplant (Solanum melongena L.). Biological Diversity and Conservation 3:1-5.

Zhang Y, Wang B, Guo L, Xu W, Wang Z, Li B, Zhang J (2018) Factors influencing direct shoot regeneration from leaves.; petioles.; and plantlet roots of triploid hybrid Populus sect. Tacamahaca. J Forestry Res 29:1533-1545. DOI: CNKI:SUN: LYYJ.0.2018-06-009

Zhang Y, Wei ZM, Xi ML, Shi JS (2006) Direct organogenesis and plantlet regeneration from mature zygotic embryos of masson pine (Pinus massoniana L.). Plant Cell Tiss Org Cult 84:119-123. DOI: 10.1007/s11240-005-9004-Z

Zhu L, Chu X, Sun T, Ye J, Wu X (2019) Micropropagation of Pinus densiflora and the evaluation of nematode resistance of regenerated microshoots in vitro. J Forestry Res 30:519-528. DOI: 10.1007/s11676-018-0681-y

Zhu LH, Wu XQ, Qu HY, Ji J, Ye JR (2010) Micropropagation of Pinus massoniana and mycorrhiza formation in vitro. Plant Cell Tiss Org Cult 102:121-128. DOI: 10.1007/s11240-010-9711-y

Zhu ML, Wang J, Yu Y, Liu SJ, Wei ZM (2007) Efficient organogenesis and plantlet regeneration in the timber species Cunninghamia lanceolata (Lamb.) hook. In Vitro Cell Dev Biol - Plant 43:449-455. DOI: 10.1007/s11627-007-9092-z 


\section{Figures}

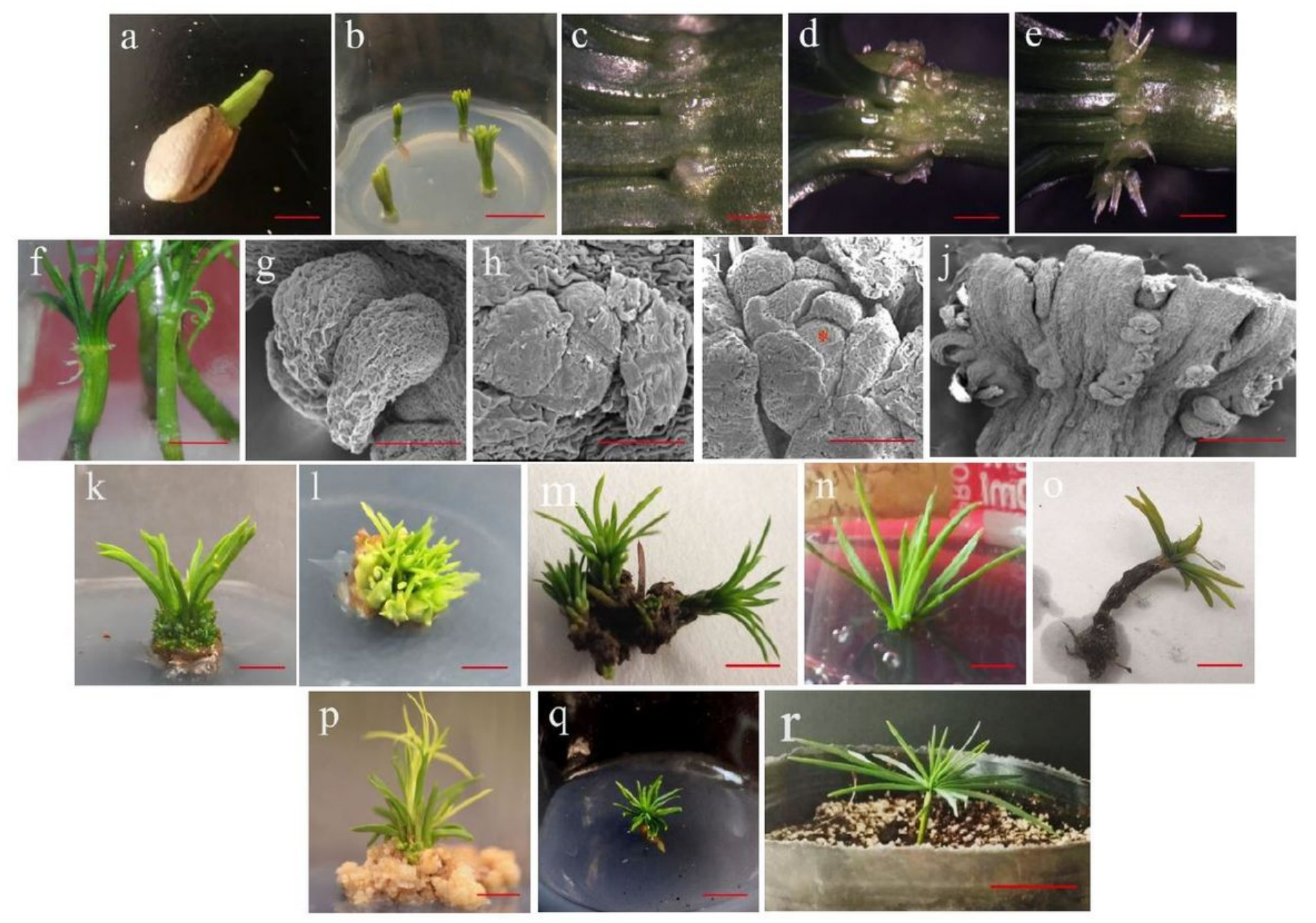

\section{Figure 1}

Establishment of the in vitro regeneration system for sprouted seeds explants of Korean pine. (a) the sprouted seeds of Korean pine (bar $=5 \mathrm{~mm}$ ); (b) explants inoculated into adventitious bud induction medium (0d) (bar = $10 \mathrm{~mm}$ ); (c) adventitious buds of Korean pine obtained by culturing for 10 days (bar = $2 \mathrm{~mm}$ ); (d) adventitious buds of Korean pine obtained by culturing for 20 days (bar $=5 \mathrm{~mm}$ ); (e $\mathrm{f}$ ) adventitious buds of Korean pine obtained by culturing for 30 days (bar $=5 \mathrm{~mm})$; $(\mathrm{g}-\mathrm{j})$ scanning electron microscopy of adventitious shoot formation from cotyledons $10(\mathrm{~g}), 20(\mathrm{~h})$, and $30(\mathrm{i}, \mathrm{j})$ days culture, respectively; (g) adventitious bud primordium and needle primordia just also formed after 7-10 days culture (bar $=2 \mathrm{~mm}$ ). (h) adventitious shoot primordia at early stage of development after 20 days culture (bar = $2 \mathrm{~mm}$ ); (i) clusters of adventitious shoots formed and the leaf sheath-like structure protecting the shoot meristem $(\mathbb{Q})$ after 30 days culture (bar $=2 \mathrm{~mm}$ ); $(\mathrm{j})$ numerous adventitious buds at different development stages simultaneously after 30 days culture (bar $=3 \mathrm{~mm}) ;(\mathrm{k})$ adventitious buds of Korean pine after elongation for 20 days (bar $=5 \mathrm{~mm}$ ); (I) adventitious buds of Korean pine after elongation for 40 days (bar $=5 \mathrm{~mm}) ;(\mathrm{m})$ adventitious buds of Korean pine after elongation for 60 days (bar $=10 \mathrm{~mm}$ ); (n) isolated individual dventitious buds that were used for rooting (bar = $10 \mathrm{~mm}$ ); (o) the deformed 
adventitious roots were produced ( $\mathrm{bar}=8 \mathrm{~mm}) ;(\mathrm{p})$ a large amount of callus formed during the rooting process $(\mathrm{bar}=10 \mathrm{~mm})$; $(\mathrm{q})$ roots were formed from elongated adventitious shoots after 60 days (bar = 15 $\mathrm{mm})$; $(\mathrm{r})$ plantlets established in potting substrate for 30 days (bar $=25 \mathrm{~mm}$ ) 